\title{
Therapeutic effects of STAT3 inhibition by nifuroxazide on murine acute graft graft-vs.-host disease: Old drug, new use
}

\author{
HUIJIE JIA ${ }^{1,2}$, JING CUI ${ }^{1}$, XIAOLONG JIA ${ }^{3}$, JINGJING ZHAO ${ }^{4}$, YUCHEN FENG ${ }^{4}$, PEIJUAN ZHAO ${ }^{3}$, \\ DAN ZANG ${ }^{5}$, JIAN YU ${ }^{5}$, TIESUO ZHAO ${ }^{3,4}$, HUI WANG $^{3}$ and KAILIN XU ${ }^{2}$ \\ ${ }^{1}$ Department of Pathology, Xinxiang Medical University, Xinxiang, Henan 453000; ${ }^{2}$ Laboratory of Transplantation \\ and Immunology, Xuzhou Medical University, Xuzhou, Jiangsu 221002; ${ }^{3}$ Henan Collaborative Innovation Center of \\ Molecular Diagnosis and Laboratory Medicine; ${ }^{4}$ Department of Immunology, Xinxiang Medical University; ${ }^{5}$ Department \\ of Pathology, The First Affiliated Hospital of Xinxiang Medical University, Xinxiang, Henan 453000, P.R. China
}

Received September 13, 2016; Accepted May 26, 2017

DOI: $10.3892 / \mathrm{mmr} .2017 .7825$

\begin{abstract}
Graft-vs.-host disease (GvHD) is a major and lethal complication of allogeneic bone marrow transplantation (allo-BMT). Although great development has been made, the treatment progress of this disorder is slow. Research has illustrated that STAT3 was critical for T cell alloactivation in GvHD. In the present study, the authors hypothesized that nifuroxazide, as the STAT3 inhibitor, treatment may attenuate the development of acute GvHD (aGvHD). The results demonstrated that nifuroxazide suppressed the development of aGvHD and significantly delayed aGvHD-induced lethality. Mice receiving nifuroxazide had mostly normal-appearing skin with minimal focal ulceration, mild edema and congestion in the liver, and a less-pronounced villus injury and less inflammatory infiltrate in the small intestine. Treatment with nifuroxazide inhibited the activation of STAT3, resulting in the regulation of the $\mathrm{CD} 4^{+} \mathrm{T}$ cells and $\mathrm{CD} 4^{+} \mathrm{CD} 25^{+} \mathrm{T}$ cells and reduction of interferon- $\gamma$ and tumor necrosis factor- $\alpha$ levels. In conclusion, nifuroxazide may be efficacious for post-transplant of GvHD, providing a potent drug for use as a prophylactic or as a second-line therapy for aGvHD in clinical trials.
\end{abstract}

\section{Introduction}

Allogeneic bone marrow transplantation (allo-BMT) can be a lifesaving therapy for a variety of malignancies and

Correspondence to: Professor Kailin Xu, Laboratory of Transplantation and Immunology, Xuzhou Medical University, 99 West Huaihai Road, Xuzhou, Jiangsu 221002, P.R. China E-mail: kailin_xxmu@163.com

Professor Hui Wang, Henan Collaborative Innovation Center of Molecular Diagnosis and Laboratory Medicine, Xinxiang Medical University, 601 Jinsui Street, Xinxiang, Henan 453000, P.R. China E-mail: wanghui@xxmu.edu.cn

Key words: nifuroxazide, signal transducer and activator of transcription 3, graft-vs.-host disease, immunotherapy non-malignant diseases. But the efficacy of allo-BMT is hampered by a major and lethal complication, graft-versus-host disease (GvHD) (1). GvHD can be classified into acute GvHD (aGvHD) and chronic GvHD (cGvHD), and aGvHD usually occurs within 100 days of allo-BMT. As a rapidly progressive syndrome, aGvHD is characterized by profound wasting, immunosuppression and tissue damage in many organs including the gut, liver and skin (2-4). aGvHD is a serious immune pathological response, in which naïve donor $\mathrm{T}$ cells recognize the host allogeneic antigen by antigen presenting cells and finally cause recipient tissue injury $(5,6)$. Increasing evidence from experiments illustrated that $\mathrm{T}$ cell activation was vital for the induction of aGvHD through dysregulating of inflammatory cytokine cascades and agents that suppressed allo-reactive $\mathrm{T}$ cells have shown promise in the therapy of aGvHD (7).

It was reported that JAK-STAT signaling had a vital role in regulating effector $\mathrm{T}$ cell differentiation, homeostasis and integrating cytokine secretion (8). As the important member of the STAT family, STAT3 is critical for T cell alloactivation in aGvHD (9-11) and prolonged activation of STAT3, which is a dominant event occurring in host T cells and GvHD targeted organs (12). Murine recipients of allo-BMT with T lymphocytes lacking STAT3 did not exhibit the typical symptoms of GvDH, but displayed conspicuous survival instead (13). Hill et al (14) reported that knockout of SOCS3, which is the negative regulator of JAK2/STAT3, markedly increased the incidence of GvHD in the mice model. In addition, several inhibitors or antibodies such as ruxolitinib, CP-690550, TG101348 and PIAS3, block the JAK2/STAT3 signaling pathway and alleviate the severity of GvHD (15-21).

Nifuroxazide has been initially identified as an intestinal broad-spectrum antibiotic since the 1980s and illustrated as a potent inhibitor of the JAK/STAT signaling recently (22). Nifuroxazide has been demonstrated to inhibit STAT3 phosphorylation by suppressing the Jak family kinases Jak2 and Tyk2, and cause a decrease in viability of myeloma cells but with no cytotoxic effect of normal peripheral blood mononuclear cells (22), illustrating the security to a certain extent in clinical practice. Although not available for clinical use in certain countries currently, nifuroxazide is available in many 
countries worldwide and may have broader efficacy as well. In the present study, the authors hypothesized that nifuroxazide therapy would attenuate the development of aGVHD using an experimental murine model.

\section{Materials and methods}

Animals and drugs. The recipient mice were 8-12-week-old $\mathrm{BALB} / \mathrm{c}$ male mice ( $\mathrm{n}=20$ per group), and the donor mice were 8-12-week-old C57BL/6 male mice. All mice were obtained from the Experimental Animal Center of Zhengzhou University (Zhengzhou, China) and were fed for about one week to adapt to the environment. Subsequently, in the next week, the recipient mice were fed with sterile food and acidified water. All experiments were performed according to the Institutional Animal Care and Use Committee Guidelines and were approved by the Ethics Committee of Xinxiang Medical University (Xinxiang, China). The nifuroxazide used was obtained from Sigma-Aldrich; Merck KGaA (Darmstadt, Germany) and dissolved in dimethylsulfoxide.

Allogeneic BMT. Prior to transplantation, the recipient mice were exposed to $7.5 \mathrm{~Gy}$ total body irradiation $\left({ }^{60} \mathrm{Co}\right.$ source). Eight donor C57BL/6 mice were sacrificed, and the bone marrow cells and the splenocytes were isolated and adjusted to $1 \times 10^{8} \mathrm{cell} / \mathrm{ml}$, respectively. Following $4 \mathrm{~h}$, the mixture of bone marrow cells $(50 \mu \mathrm{l})$ and the splenocytes $(50 \mu \mathrm{l})$ from donor mice were injected through tail veins.

Treatment with nifuroxazide. The entire recipient mice were divided randomly into two groups with 20 mice each group. The drug of nifuroxazide $(2 \mathrm{mg} / \mathrm{ml})$ was continuously injected intravenously into the recipient mice (100 $\mu \mathrm{l} / \mathrm{mouse})$ at 4-11 days following transplantation, while the control group received saline. The survival time, clinical manifestations and body weight changes were monitored over time and the clinical scores of aGVHD were made according to the work of Cooke et al (23).

Western blotting. Liver tissues were collected from nifuroxazide-treated and saline-treated mice of the allo-BMT model respectively. Tissues were lysed in radioimmunoprecipitation assay buffer [20 mM Tris- $\mathrm{HCl}(\mathrm{pH} 7.5), 150 \mathrm{mM} \mathrm{NaCl}, 1 \mathrm{mM}$ $\mathrm{Na}_{2}$ EDTA, 1 mM EGTA, 1\% NP-40, $1 \%$ sodium deoxycholate, $2.5 \mathrm{mM}$ sodium pyrophosphate, $1 \mathrm{mM}$ b-glycerophosphate, $1 \mathrm{mM} \mathrm{Na} \mathrm{VO}_{4}, 1 \mathrm{mg} / \mathrm{ml}$ leupeptin]. Protein concentration was determined using a bicinchoninic protein assay kit (cat no. P0012S; Beyotime Institute of Biotechnology, Haimen, China). A total of $50 \mu \mathrm{g}$ sample per lane was separated by $12 \%$ SDS-PAGE and then transferred to a polyvinylidene difluoride membrane. Membranes were blocked in bovine serum albumin blocking buffer (cat no. P0023B; Beyotime Institute of Biotechnology) for $1 \mathrm{~h}$ at room temperature. Subsequently, membranes were stained with primary antibodies against $\beta$-actin $(1: 1,000)$, STAT3 (1:1,000) and p-STAT3 (1:500) (cat nos. 3700, 9139 and 9145 respectively; Cell Signaling Technology, Inc., Danvers, MA, USA) at $4^{\circ} \mathrm{C}$ overnight, and subsequently incubated with an appropriate horseradish peroxidase-conjugated secondary antibody $(1: 2,000$; cat nos. 129256, 127655; OriGene Technologies, Inc., Rockville,
$\mathrm{MD}, \mathrm{USA}$ ) for $1 \mathrm{~h}$ at room temperature. Finally, the immunocomplexes were visualized using a BeyoECL Plus kit (Beyotime Institute of Biotechnology). The gray analysis of bands were quantified using Quantity One software (version 4.62; Bio-Rad Laboratories, Inc., Hercules, CA, USA).

Histopathological analysis. Following treatment for ten days, the liver and small intestine from mice in the GvHD control group and nifuroxazide-treated group were fixed in $4 \%$ paraformaldehyde and then the tissues were sectioned at $7 \mu \mathrm{m}$ thicknesses, deparaffinized using xylene, then dehydrated using a gradient of ethanol, and finally stained with hematoxylin and eosin.

Flow cytometry analysis. Spleens were isolated and harvested at 2 weeks following allo-BMT, passed through a $40 \mathrm{~mm}$ nylon cell strainer filter, and then collected in PBS. RBCs were removed with Red Blood Cell Lysis buffer (Beyotime Institute of Biotechnology, Haimen, China). Cells were washed and resuspended in PBS at $1 \times 10^{7}$ cells $/ \mathrm{ml}$. A total of $100 \mu \mathrm{l}$ resuspended cells were placed on ice and labeled with anti-CD3, anti-CD4, anti-CD8, and anti-CD25 (cat nos. 05112-50-100, 06112-80-25, 10112-60-25, 07312-60-25; PeproTech, Inc., Rocky Hill, NJ, USA) labeled with appropriate fluorochrome for $30 \mathrm{~min}$ in the dark. Then cells were washed with iced PBS twice and resuspended in $1 \%$ paraformaldehyde. The fluorescence intensity of cell was measured with flow cytometer (Guava easyCyte; EMD Millipore, Billerica, MA, USA) with a minimum of 10,000 cells collected.

ELISA. The peripheral blood was collected at day 14 following transplantation, and the levels of tumor necrosis factor- $\alpha$ and interferon $-\gamma$ in plasma were analyzed by ELISA kits (cat nos. 0608150430 and 0608150421; RayBiotech, Norcross, GA, USA) according to the manufacturer's instructions.

Statistical analysis. Student's t-tests or one-way analysis of variance were performed to test whether mean values between different groups were significantly different when appropriate. For survival analysis, Kaplan-Meier method with log-rank test was used. $\mathrm{P}<0.05$ was considered to indicate a statistically significant difference.

\section{Results}

Treatment of nifuroxazide ameliorated the symptoms of the recipient mice with $a G v H D$ and improved their living time. Although prophylactic treatment for aGVHD is important, perhaps equally important is the therapy for established GVHD, which is usual refractory to frontline therapy (24). The intravenous (i.v.) injection of lethally irradiated BALB/c mice with $5 \times 10^{6}$ total bone marrow cells and $5 \times 10^{6}$ splenocytes from C57BL/6 donors leads to aGVHD, which is characterized by gradual weight loss, depilation, lassitude, diarrhea and death. Thus, to determine whether nifuroxazide treatment could modulate the development of aGVHD, nifuroxazide was injected intraperitoneal (i.p.) to the mice following allo-BMT as described previously. Compared with the saline-treated group, the mice in the nifuroxazide-treated group showed attenuation of weight loss and less severe clinical scores of 
aGVHD (Fig. 1A and B). Moreover, the mean survival time of mice in the nifuroxazide treatment group extension was longer than the control group (Fig. 1C). These results demonstrated that aGVHD mice treated with the nifuroxazide suppressed the development of aGVHD and significantly delayed aGVHD-induced lethality.

The damage of GVHD target organs were alleviated by nifuroxazide. A hallmark of aGVHD is tissue injury and inflammation in target organs including the skin, liver and intestinal tract. When observed 2 weeks following HSCT (hematopoietic stem cell transplantation), saline-treated mice exhibited marked inflammation with pustule formation and ulceration in the skin, ballooning degeneration and severe hepatic congestion in the liver, and blunting of villi, glandular organ rupture and an inflammatory infiltrate in the lamina propria of the small intestine. In contrast, mice receiving nifuroxazide had mostly normal-appearing skin with minimal focal ulceration, mild edema and hepatic congestion in the liver, and a less-pronounced injury in the small intestine (Fig. 2).

Nifuroxazide controlled the development of aGVHD through STAT3 modulation in a mouse model of allo-BMT. As nifuroxazide was proven as the inhibitor of STAT3, in addition to the vital role in the pathogenesis of GVHD, the authors next investigated whether this drug could affect STAT3 activity. Western blotting was carried out to quantify the STAT3 activity. The results showed that p-STAT3 activities in liver isolated from each group were noticeably decreased by nifuroxazide treatment (Fig. 3).

Nifuroxazide therapy inhibited effect $T$ cells activation and regulated $\mathrm{CD}^{+} \mathrm{CD} 25^{+} \mathrm{T}$ cells expression. The inflammatory processes that observed in aGVHD target organs are driven by the $\mathrm{T}$ lymphocytes activation (25). Correspondingly, less $\mathrm{CD} 4^{+}$but not $\mathrm{CD}^{+} \mathrm{T}$ lymphocytes were identified in the spleen of mice treated with nifuroxazide than in saline-treated controls (Fig. 4A and B). As the $\mathrm{CD} 4{ }^{+} \mathrm{CD} 25^{+} \mathrm{T}$ cells serve a negative role in GVHD progression (26), the authors next detected the $\mathrm{CD} 4{ }^{+} \mathrm{CD} 25^{+} \mathrm{T}$ cells following nifuroxazide treatment. The results demonstrated that when compared with the saline treated group, number of $\mathrm{CD} 4{ }^{+} \mathrm{CD} 25^{+} \mathrm{T}$ cells in nifuroxazide treated group was significantly increased (Fig. 4C), indicating that the therapeutic effect using nifuroxazide partly not only due to the inhibition of the $\mathrm{CD} 4^{+} \mathrm{T}$ cells but also due to the increase of the $\mathrm{CD} 4{ }^{+} \mathrm{CD} 25^{+} \mathrm{T}$ cells. The small but statistically significant increase in $\mathrm{CD} 4^{+} \mathrm{CD} 25^{+} \mathrm{T}$ cells is consistent with the possibility that the increase of $\mathrm{CD} 4{ }^{+} \mathrm{CD} 25^{+} \mathrm{T}$ cells contributes to the efficacy of the drug.

Treated with nifuroxazide suppressed the production of inflammatory cytokine. The progression of aGvHD is accompanied by producing and releasing proinflammatory cytokines $(27,28)$. Recipient mice were irradiated and transplanted with total bone marrow cells and splenocytes cells and then were injected with either nifuroxazide or saline as before. Serum samples from each group were analyzed on day 14 following transplantation for detecting levels of IFN- $\gamma$ and TNF- $\alpha$. The authors reported that two weeks after allo-BMT,
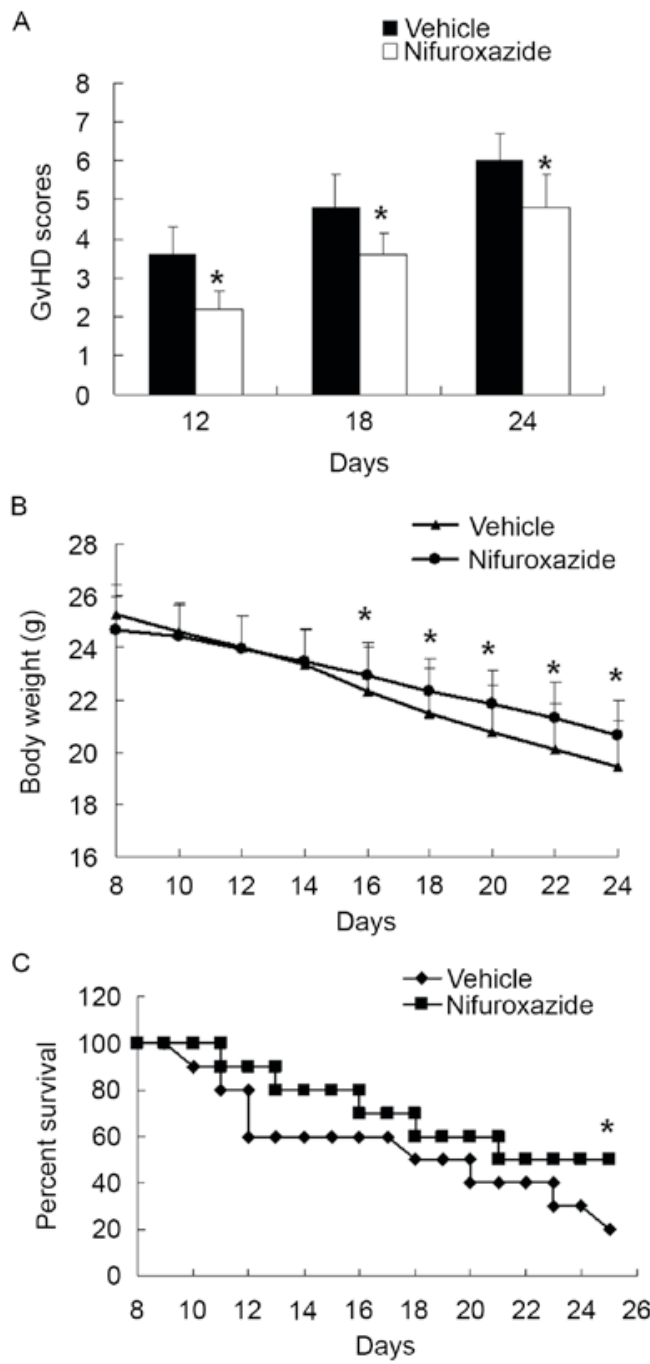

Figure 1. Nifuroxazide attenuated the severity and mortality from aGvHD. Recipient of BALB/c mice were received the cell mixture of 5x106 total bone marrow cells and $5 \times 10^{6}$ splenocytes from C57BL/6 mice, and nifuroxazide or saline was injected on day 4 post allo-BMT. (A) aGvHD scores obtained from different treated mice. (B) Body weight change of mice in each group. (C) The survival rate of mice following treatment. ${ }^{*} \mathrm{P}<0.05$ vs. vehicle group. Data were combined from two independent experiments and are represented as the mean \pm standard deviation.

serum levels of IFN- $\gamma$ and TNF- $\alpha$ were aggrandized above baseline in saline-treated mice, while the circulating levels of these cytokines were reduced by nifuroxazide treatment (Fig. 5).

\section{Discussion}

Though the pathophysiology of aGvHD is complicated, accumulating evidence suggests that suppression the activity of alloreactive $\mathrm{T}$ cells can potentially limit the morbidity associated with the disorder. However, many agents carry with obvious side effects that restrict their usage, such as delayed immune reconstitution and increased incidence of infection (24). The induction of aGvHD is a process of donor T cells response to host alloantigens and causes T-cell mediated tissue damage. It is worth noting that STAT3 binds to its ligands and triggers the allogeneic $\mathrm{T}$ cells activation. Nifuroxazide, which is used as an antimicrobial drug, has been demonstrated 

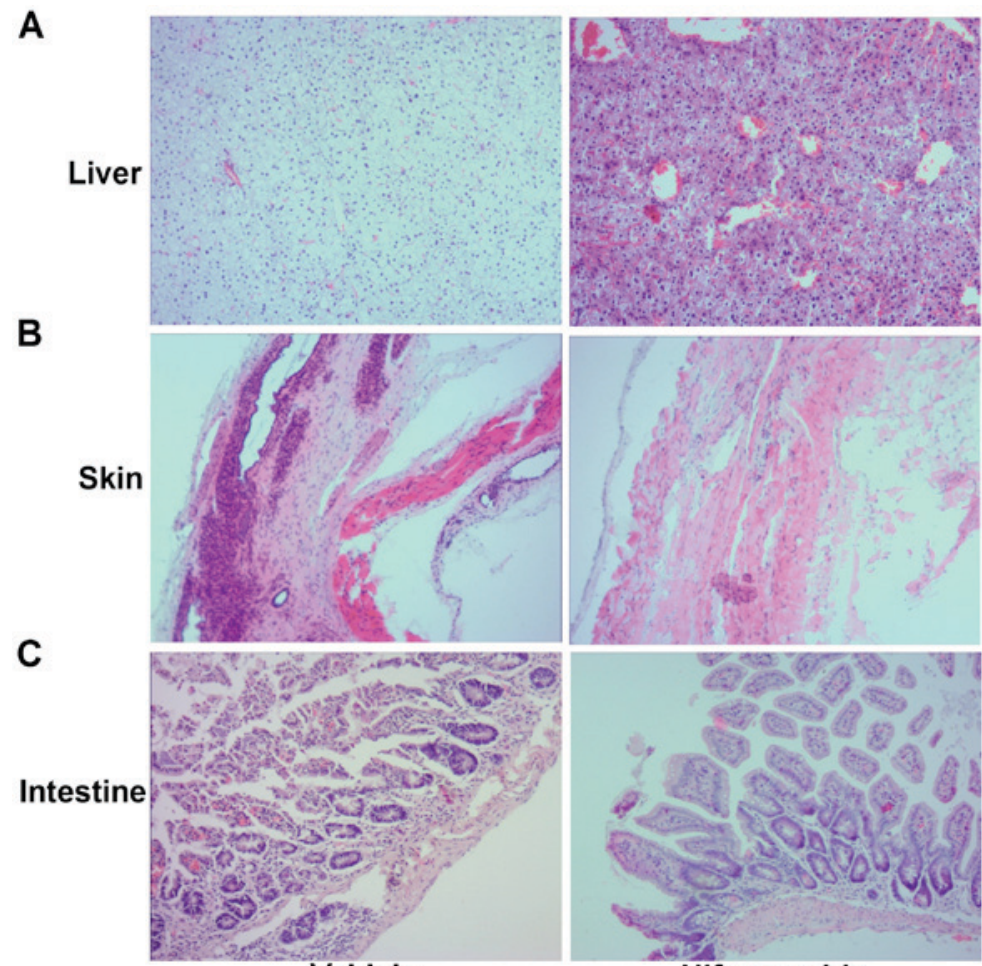

Vehicle

\section{Nifuroxazide}

Figure 2. Histopathology of acute graft vs. host disease target tissues following allogeneic bone marrow transplantation. Lethally irradiated BALB/c mice were underwent transplantation with bone marrow cells and splenocytes. Mice that received transplantation were treated by nifuroxazide or saline. The section was stained with hematoxylin and eosin (magnification, x100). Examination in the (A) liver, (B) skin and (C) small intestine.

A

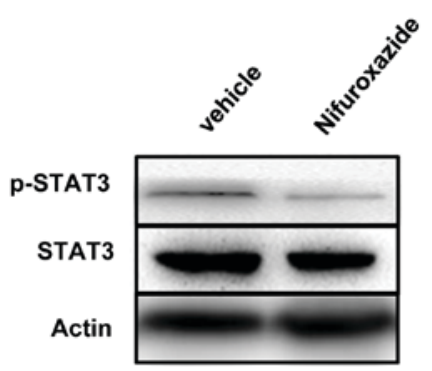

B

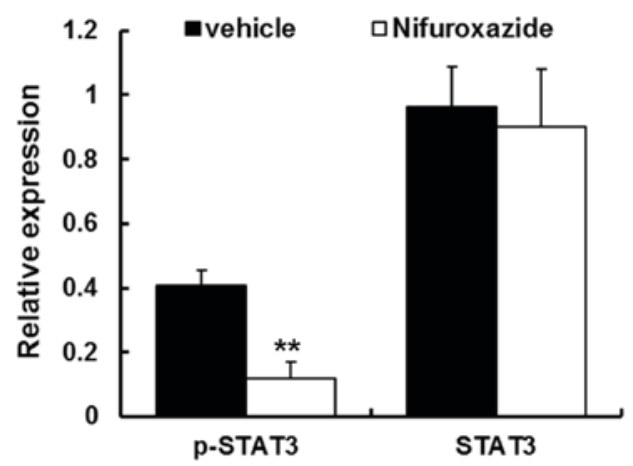

Figure 3. Nifuroxazide blocked STAT3 expression in liver of mice with acute graft vs. host disease. (A) At 14 days following allogeneic bone marrow transplantation, western blotting was performed for STAT3 and p-STAT3 expression. (B) Bar graph indicates the relative expression of STAT3 and p-STAT3. ${ }^{* *} \mathrm{P}<0.01$ vs. vehicle group. Data are represented as the mean \pm standard deviation. STAT3 signal transducer and activator of transcription 3; p-, phosphorylated..

the potent of STAT3 inhibitor, and exhibits antitumor effect both in hematological malignancy and solid tumors. There are numerous STAT3 inhibitors. Among them, the authors chose nifuroxazide because of the safeness currently available $(22,29,30)$. The intended effect of nifuroxazide was observed, i.e. blocking STAT3 by inhibiting its phosphorylation, however, it was unclear whether the nifuroxazide could prevent GvHD.

As previously reported, lethal TBI (total body irradiation) can destroy the immune system and result in an immunodeficiency state of mice (31). The experiments in the current study still indicated that the mice with TBI and without any particular treatment exhibited an obvious body weight loss within two days, and would die from irradiation related damage or infection very soon. Nevertheless, the mice engrafted the donor $\mathrm{T}$ cells exhibited the characteristic of severe GvHD, including less activity, arched back and ruffled fur, which led to their intestine, liver skin injury and even death.

The doses of nifuroxazide used in the experiment are derived from the articles and pre-experiments. Injections occurred daily when administration was delayed until 7 days following allogeneic BMT. The results demonstrated that post-treatment of nifuroxazide reduced the incidence and severity of mice with aGvHD, whereas a previous article reported that post-treatment using JAK2 inhibition ameliorated GvHD syndromes (32). Consequently, the histopathology 

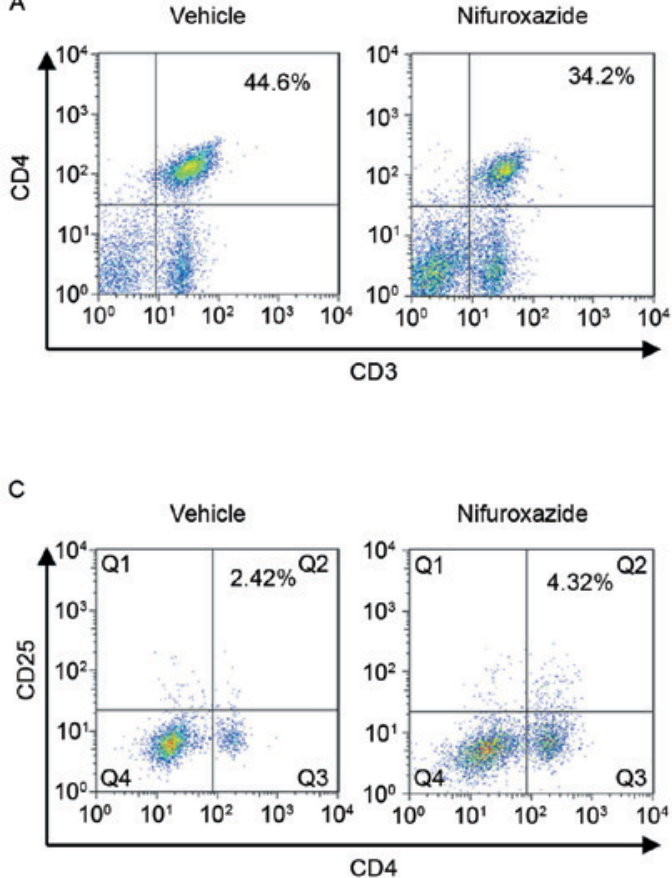
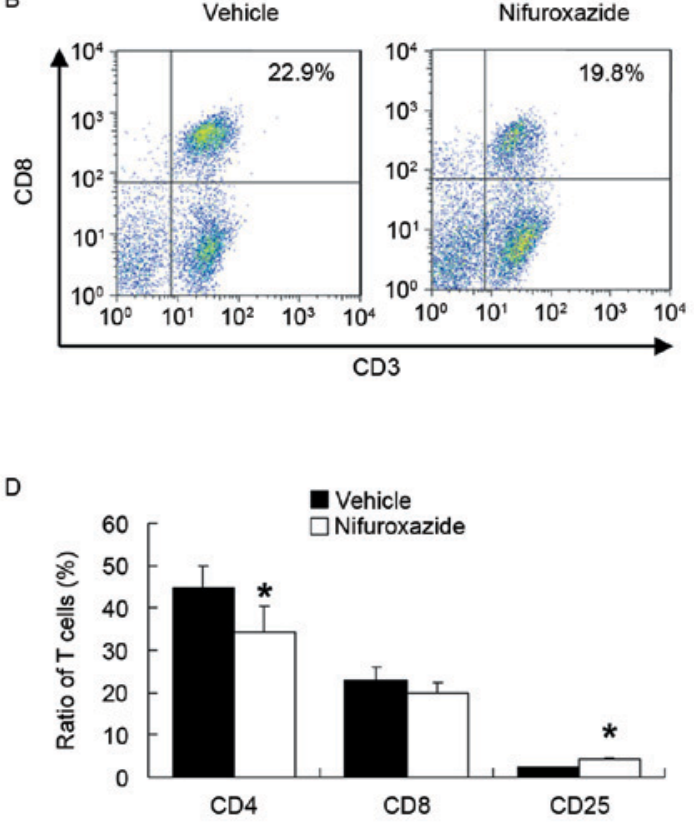

Figure 4. Nifuroxazide affected T cells proportion. At 14 days following allogeneic bone marrow transplantation, splenocytes were isolated from each group, stained with relevant antibody, and then analyzed by flow cytometry. The expression of (A) $\mathrm{CD}^{+}$, (B) $\mathrm{CD}^{+}$and (C) CD25 $5^{+} \mathrm{T}$ cells in the spleen. (D) The bars represent the average ratio of each $\mathrm{T}$ cells are the bar graph represents the mean \pm standard deviation. ${ }^{*} \mathrm{P}<0.05$ vs. vehicle group.
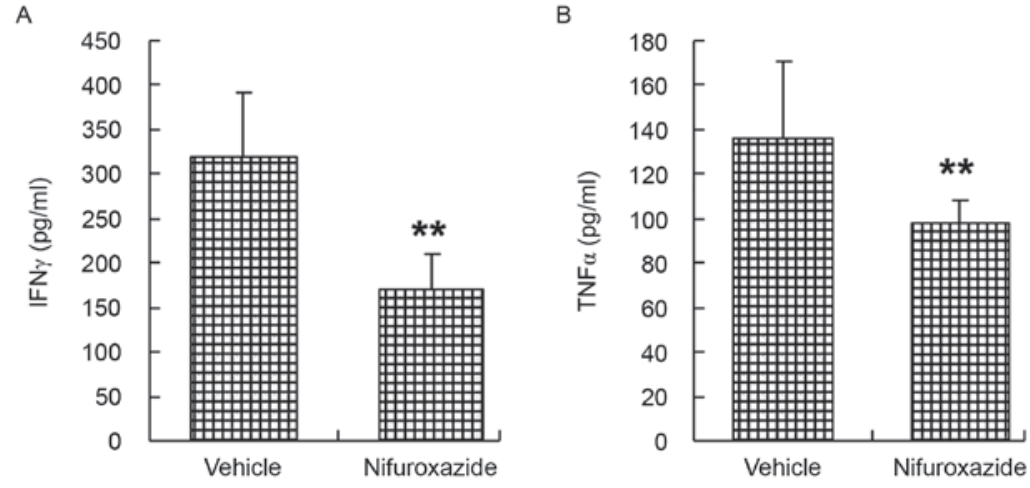

Figure 5. Injection of nifuroxazide inhibited proinflammatory cytokine production. BALB/c mice were exposed to 7.5 Gy of total-body irradiation and transplanted with bone marrow cells and splenocytes from C57BL/6 donors. Each recipient was injected with nifuroxazide or saline on day 4 for one week. Sera from the mice in each group ( $\mathrm{n}=5 /$ group) were obtained on day 14 following allogeneic bone marrow transplantation and analyzed for (A) IFN- $\gamma$ and (B) TNF- $\alpha{ }^{* *} \mathrm{P}<0.01$ vs. vehicle group. IFN, interferon; TNF, tumor necrosis factor.

observation demonstrated a decrease of damage in the target organs.

The authors then investigated whether the immunosuppressive effects of nifuroxazide on GvHD, which blocked STAT3 activation, stemmed from the decrease of alloreactive T-cells. It has been suggested that, following BMT, alloreative $\mathrm{T}$ cells enter peripheral lymphoid organs rapidly within hours, while alloreactive $\mathrm{T}$ lymphocytes migrate to target organs slowly within a few days $(25,33)$. Flow cytometry indicated that STAT3 blockage with nifuroxazide significantly reduced CD4 ${ }^{+} \mathrm{T}$ lymphocytes activation in spleens at day 14 .

Furthermore, the dysregulation of inflammatory cytokine cascades in aGvHD initiation is known to serve a critical role in the pathogenesis of aGvHD. In particular, IFN- $\gamma$ (34-36) and TNF- $\alpha$ (37) have been established as vital effector factors of tissue damage originating from BMT-conditioning regimen. A marked decrease was identified in the concentrations of IFN- $\gamma$ and TNF- $\alpha$ in plasma following nifuroxazide treatment. Though not detected, nuclear factor- $\kappa \mathrm{B}$, a proinflammatory transcription factor, having a crosstalk both with STAT3 and TLR9 signaling pathway, may also be inhibited in the treatment. The immunological effects of nifuroxazide need to be clearly illustrated through further researches.

So far, the drugs, as the therapeutic approaches of GvHD, have usually resulted in severe immunosuppression occurring at the expense of graft-versus-leukemia, while through inhibiting STAT3 signaling pathway, nifuroxazide has proven the antitumor effects in hematological oncology (22) and solid tumors $(38,39)$, suggesting that apart from attenuating the symptom of GvHD, treatment with nifuroxazide has the 
potential to be a potent antitumor agent. Most importantly, there were no observed severe side effects from the experiment. Further studies ought to be carried out to detect the effect of prophylactic application of nifuroxazide on GvHD (including aGvHD or cGvHD).

In conclusion, the current study illustrated that nifuroxazide therapy may attenuate GvHD and improve the survival rate, and the existence of a potential effect in terms of regulating $\mathrm{T}$ cell differentiation, with a significant decrease in the secretion of IFN- $\gamma$ and TNF- $\alpha$ cytokines. These effects were mediated by the blockade of the STAT3 pathways. On this basis, these observations illustrated that the nifuroxazide may be efficacious for post-transplant of GvHD, providing a potent clinical choice as a prophylactic or as a second-line therapy for aGvHD.

\section{Acknowledgements}

The current study was supported by the National Natural Science Foundation of China (grant nos. 81300442 and 81301947) and grants from the Scientific Research Fund of Xinxiang Medical University (grant nos. 2013QN112 and 2014QN115) and the doctor launch fund of Xinxiang Medical University (grant nos. 505016, 505017).

\section{References}

1. Gratwohl A, Baldomero H and Passweg J: Hematopoietic stem cell transplantation activity in Europe. Curr Opin Hematol 20 485-493, 2013.

2. Blazar BR, Murphy WJ and Abedi M: Advances in graft-versus-host disease biology and therapy. Nat Rev Immunol 12: 443-458, 2012.

3. Socié G and Blazar BR: Acute graft-versus-host disease: From the bench to the bedside. Blood 114: 4327-4336, 2009.

4. Wysocki CA, Panoskaltsis-Mortari A, Blazar BR and Serody JS: Leukocyte migration and graft-versus-host disease. Blood 105: 4191-4199, 2005.

5. Anderson BE, Zheng $\mathrm{H}$, Taylor PA, Matte-Martone $\mathrm{C}$, McNiff JM, Jain D, Demetris AJ, Panoskaltsis-Mortari A, Ager A, Blazar BR, et al: Memory T cells in GVHD and GVL. Biol Blood Marrow Transplant 14 (1 Suppl 1): S19-S20, 2008.

6. Shlomchik WD, Couzens MS, Tang CB, McNiff J, Robert ME, Liu J, Shlomchik MJ and Emerson SG: Prevention of graft versus host disease by inactivation of host antigen-presenting cells Science 285: 412-415, 1999.

7. Li Pira G, Di Cecca S, Montanari M, Moretta L and Manca F: Specific removal of alloreactive T-cells to prevent GvHD in hemopoietic stem cell transplantation: Rationale, strategies and perspectives. Blood Rev 30: 297-307, 2016.

8. Spoerl S, Mathew NR, Bscheider M, Schmitt-Graeff A, Chen S, Mueller T, Verbeek M, Fischer J, Otten V, Schmickl M, et al: Activity of therapeutic JAK $1 / 2$ blockade in graft-versus-host disease. Blood 123: 3832-3842, 2014.

9. Lu SX, Alpdogan O, Lin J, Balderas R, Campos-Gonzalez R, Wang X, Gao GJ, Suh D, King C, Chow M, et al: STAT-3 and ERK $1 / 2$ phosphorylation are critical for T-cell alloactivation and graft-versus-host disease. Blood 112: 5254-5258, 2008.

10. Fujino $\mathrm{M}$ and Li XK: Role of STAT3 in regulatory T lymphocyte plasticity during acute graft-vs.-host-disease. JAKSTAT 2: e24529, 2013.

11. Radojcic V, Pletneva MA, Yen HR, Ivcevic S, Panoskaltsis-Mortari A, Gilliam AC, Drake CG, Blazar BR and Luznik L: STAT3 signaling in $\mathrm{CD} 4^{+} \mathrm{T}$ cells is critical for the pathogenesis of chronic sclerodermatous graft-versus-host disease in a murine model. J Immunol 184: 764-774, 2010.

12. Ma HH, Ziegler J, Li C, Sepulveda A, Bedeir A, Grandis J, Lentzsch S and Mapara MY: Sequential activation of inflammatory signaling pathways during graft-versus-host disease (GVHD): Early role for STAT1 and STAT3. Cell Immunol 268: 37-46, 2011.
13. Laurence A, Amarnath S, Mariotti J, Kim YC, Foley J, Eckhaus M, O'Shea JJ and Fowler DH: STAT3 transcription factor promotes instability of nTreg cells and limits generation of iTreg cells during acute murine graft-versus-host disease. Immunity 37: 209-222, 2012.

14. Hill GR, Kuns RD, Raffelt NC, Don AL, Olver SD, Markey KA, Wilson YA, Tocker J, Alexander WS, Clouston AD, et al: SOCS3 regulates graft-versus-host disease. Blood 116: 287-296, 2010.

15. Chen X, Das R, Komorowski R, Beres A, Hessner MJ, Mihara M and Drobyski WR: Blockade of interleukin-6 signaling augments regulatory $\mathrm{T}$-cell reconstitution and attenuates the severity of graft-versus-host disease. Blood 114: 891-900, 2009.

16. Lee SH, Moon SJ, Park MJ, Kim EK, Moon YM and Cho ML: PIAS3 suppresses acute graft-versus-host disease by modulating effector T and B cell subsets through inhibition of STAT3 activation. Immunol Lett 160: 79-88, 2014.

17. Carniti C, Gimondi S, Vendramin A, RecordatiC, Confalonieri D, Bermema A, Corradini P and Mariotti J: Pharmacologic inhibition of JAK1/JAK2 signaling reduces experimental murine acute GVHD while preserving GVT effects. Clin Cancer Res 21: 3740-3749, 2015.

18. Jaekel N, Behre G, Behning A, Wickenhauser C, Lange T, Niederwieser D and Al-Ali HK: Allogeneic hematopoietic cell transplantation for myelofibrosis in patients pretreated with the JAK1 and JAK2 inhibitor ruxolitinib. Bone Marrow Transplant 49: 179-184, 2014.

19. Park HB, Oh K, Garmaa N, Seo MW, Byoun OJ, Lee HY and Lee DS: CP-690550, a Janus kinase inhibitor, suppresses CD4 ${ }^{+}$ T-cell-mediated acute graft-versus-host disease by inhibiting the interferon- $\gamma$ pathway. Transplantation 90: 825-835, 2010.

20. Betts BC, Abdel-Wahab O, Curran SA, St Angelo ET, Koppikar P, Heller G, Levine RL and Young JW: Janus kinase-2 inhibition induces durable tolerance to alloantigen by human dendritic cell-stimulated $\mathrm{T}$ cells yet preserves immunity to recall antigen. Blood 118: 5330-5339, 2011.

21. Tawara I, Koyama M, Liu C, Toubai T, Thomas D, Evers R, Chockley P, Nieves E, Sun Y, Lowler KP, et al: Interleukin-6 modulates graft-versus-host responses after experimental allogeneic bone marrow transplantation. Clin Cancer Res 17: 77-88, 2011.

22. Nelson EA, Walker SR, Kepich A, Gashin LB, Hideshima T, Ikeda H, Chauhan D, Anderson KC and Frank DA: Nifuroxazide inhibits survival of multiple myeloma cells by directly inhibiting STAT3. Blood 112: 5095-5102, 2008.

23. Cooke KR, Kobzik L, Martin TR, et al: An experimental model of idiopathic pneumonia syndrome after bone marrow transplantation: I. The roles of minor $\mathrm{H}$ antigens and endotoxin. Blood 88: 3230-3239, 1996.

24. Kim SS: Treatment options in steroid-refractory acute graft-versus-host disease following hematopoietic stem cell transplantation. Ann Pharmacother 41: 1436-1444, 2007.

25. Beilhack A, Schulz S, Baker J, Beilhack GF, Wieland CB, Herman EI, Baker EM, Cao YA, Contag CH and Negrin RS: In vivo analyses of early events in acute graft-versus-host disease reveal sequential infiltration of T-cell subsets. Blood 106: 1113-1122, 2005

26. Dijke IE, Hoeppli RE, Ellis T, Pearcey J,Huang Q, McMurchy AN, Boer K, Peeters AM, Aubert G, Larsen I, et al: Discarded human thymus is a novel source of stable and long-lived therapeutic regulatory T Cells. Am J Transplant 16: 58-71, 2016.

27. Fujii N, Hiraki A, Aoe K, Murakami T, Ikeda K, Masuda K, Matsuo K, Shinagawa K, Ishimaru F, Sugi K, et al: Serum cytokine concentrations and acute graft-versus-host disease after allogeneic peripheral blood stem cell transplantation: Concurrent measurement of ten cytokines and their respective ratios using cytometric bead array. Int J Mol Med 17: 881-885, 2006.

28. Ju XP, Xu B, Xiao ZP, Li JY, Chen L, Lu SQ and Huang ZX: Cytokine expression during acute graft-versus-host disease after allogeneic peripheral stem cell transplantation. Bone Marrow Transplant 35: 1179-1186, 2005.

29. Cipolla BG, Havouis R and Moulinoux JP: Polyamine contents in current foods: A basis for polyamine reduced diet and a study of its long term observance and tolerance in prostate carcinoma patients. Amino Acids 33: 203-212, 2007.

30. Cipolla BG, Havouis R and Moulinoux JP: Polyamine reduced diet (PRD) nutrition therapy in hormone refractory prostate cancer patients. Biomed Pharmacother 64: 363-368, 2010.

31. Qiao S, Ren H, Shi Y and Liu W: Allogeneic compact bone-derived mesenchymal stem cell transplantation increases survival of mice exposed to lethal total body irradiation: A potential immunological mechanism. Chin Med J (Engl) 127: 475-482, 2014. 
32. Joly F, Breton M, Wolf C, Ninio E and Colard O: Heterogeneity of arachidonate and paf-acether precursor pools in mast cells. Biochim Biophys Acta 1125: 305-312, 1992.

33. Panoskaltsis-Mortari A, Price A, Hermanson JR, Taras E, Lees C, Serody JS and Blazar BR: In vivo imaging of graft-versus-host-disease in mice. Blood 103: 3590-3598, 2004

34. Burman AC, Banovic T, Kuns RD, Clouston AD, Stanley AC, Morris ES, Rowe V, Bofinger H, Skoczylas R, Raffelt N, et al: IFNgamma differentially controls the development of idiopathic pneumonia syndrome and GVHD of the gastrointestinal tract. Blood 110: 1064-1072, 2007.

35. Delisle JS, Gaboury L, Bélanger MP, Tassé E, Yagita H and Perreault C: Graft-versus-host disease causes failure of donor hematopoiesis and lymphopoiesis in interferon-gamma receptor-deficient hosts. Blood 112: 2111-2119, 2008.
36. Yi T, Chen Y, Wang L, Du G, Huang D, Zhao D, Johnston H, Young J, Todorov I, Umetsu DT, et al: Reciprocal differentiation and tissue-specific pathogenesis of Th1, Th2, and Th17 cells in graft-versus-host disease. Blood 114: 3101-3112, 2009.

37. Couriel D, Saliba R, Hicks K, Ippoliti C, de Lima M, Hosing C, Khouri I, Andersson B, Gajewski J, Donato M, et al: Tumor necrosis factor-alpha blockade for the treatment of acute GVHD. Blood 104: 649-654, 2004.

38. Zhu Y, Ye T, Yu X, Lei Q, Yang F, Xia Y, Song X, Liu L, Deng H, Gao T, et al: Nifuroxazide exerts potent anti-tumor and anti-metastasis activity in melanoma. Sci Rep 6: 20253, 2016.

39. Yang F, Hu M, Lei Q, Xia Y, Zhu Y, Song X, Li Y, Jie H, Liu C, Xiong Y, et al: Nifuroxazide induces apoptosis and impairs pulmonary metastasis in breast cancer model. Cell Death Dis 6: e1701, 2015. 